\title{
FACTORS DRIVING USAGE OF FINANCIAL SERVICES FROM DIFFERENT FINANCIAL ACCESS STRANDS IN KENYA
}

\author{
Alfred Ouma Shem ${ }^{1}$, Roseline Misati and Lucas NJOroge
}

\begin{abstract}
This study uses data from the 2006 and 2009 national financial access (FinAccess) surveys to examine factors influencing financial service choices that households make. The findings indicate that households' access to financial services is based on levels of education, access to a saving facility, availability of M-Pesa services, age, group affiliations and wealth. The study further indicates that about a third of the adult population does not use any form of financial services available. Based on the results, the study recommends innovative marketing strategies aimed at expanding the use of mobile phones, which are valuable beyond the voice service and recoup costs from their increased usage; increased investment in financial education; and better designed financial products by the private sector appropriate for the unbanked majority.
\end{abstract}

Key Words: Financial Access, Access Strands and Usage.

\section{INTRODUCTION}

Expanding access to financial services to the poor, who are largely unbanked, has the potential to increase their incomes and impact directly on poverty reduction. The FinAccess 2009 survey estimated the proportion of the unbanked adult population and the proportion accessing services from the informal financial strand at $32.7 \%$ and $26.8 \%$, respectively. The majority $(59.5 \%)$ of the population therefore has no access to formal and semi-formal financial services. Access to financial services from these two strands of the financial sector is, however, key to boosting incomes and reducing poverty. This is because their services are relatively cheaper and more sustainable compared to the usurious and frequently resource starved services of the informal sector.

1 Corresponding author - Email: shemao@centralbank.go.ke. Research and Policy Analysis Department Central Bank of Kenya, P. O. Box 60000 - 00200, Nairobi, Kenya. 
In Kenya, the development of the financial sector is critical in the realization of the vision 2030, in which the sector is one of the priority areas under the economic pillar. Its crucial role is to intermediate financial resources efficiently, channelling investments to businesses that yield highest returns. This emphasis also captures the sector's increasing importance in boosting the economy, generating a rising contribution to real GDP from $3.5 \%$ in 2005 to $4.8 \%$ in 2007 and $5.7 \%$ in 2009. The sector was one of the key drivers of economic recovery expanding by $4.6 \%$ in 2009 compared to $2.7 \%$ in 2008 (Economic Survey 2010).

Although Kenya's financial sector is relatively developed and diversified compared to many countries in Sub-Saharan Africa, it has only met a modest fraction of the growing demand for its services, especially from poorer households, micro, small and medium enterprises (MSMEs) located largely in the rural and peri-urban areas. Access to financial services increased by only $5.7 \%$, which shows a reduction in financial exclusion from $38.4 \%$ in 2006 to 32.7\% in 2009 (Financial National Access Surveys 2006 and 2009).

It is important to understand and identify the behaviour of poor households in different market segments in order to formulate policies for enhancing financial inclusion and reduce poverty. Ouma (2002) examined the choice problem amongst entrepreneurs of the MSMEs in urban Kenya ${ }^{2}$. The study's findings illustrated that both institutional and individual attributes mattered for this category of users of financial services. Since 2002, two surveys on financial access have revealed that new aspects of financial developments both at institutional and product levels have evolved. This study seeks to incorporate the new developments in the financial sector by analysing the factors that households consider in their choices of financial services from different financial access strands.

\subsection{Importance of the financial sector}

In market-based economies, the financial sector has a special financial intermediation role. Financial institutions mobilize savings for investment; facilitate and encourage inflows of foreign capital (Foreign Direct Investment FDI, Portfolio investments and bonds, and remittances); optimise the allocation of resources between competing investments thereby ensuring allocation of resources to their most productive use; and price risks accordingly. The better the financial sector fulfils these roles, the better the economy per-

2 The sample used to conduct the study was drawn from the sprawling Gikomba and Kibuye open air markets in Nairobi and Kisumu, respectively. 
forms. A broad range of financial services designed to fulfil these roles include credit, savings, investments, money transfer and insurance services among others. These financial products, when well designed for different market segments including the poor, can accelerate the pace of economic development and growth by efficiently mobilizing savings, pricing risks, providing information about investment opportunities, monitoring borrowers and exerting corporate control and facilitating exchange of commodities (Levine 1997). In addition, a well functioning financial sector not only promotes economic development and growth, but also improves incomes and reduces poverty.

\subsection{Kenya's Financial Sector}

Kenya's financial sector, like in many developing countries especially in Africa, is dualistic, consisting of the formal and informal financial sectors coexisting side by side. Whereas the formal is growing, e.g., from $18.9 \%$ in 2006 to $22.6 \%$ in 2009 , the informal still remains large with majority of the adult population accessing financial services from it. This dualistic financial structure does not serve the entire population in terms of the financial services they demand. Nearly one third, as mentioned earlier, remains without access to financial services - formal or informal (FinAccess 2009 Report) 3 .

The formal financial sector, nonetheless, is relatively large and developed compared to most countries in SSA, with a large banking sector. It consists of the Banking, Capital markets, Insurance, Pensions, Savings and Credit Cooperative Societies (SACCOs) sectors. The sub-sectors are supervised by different independent regulators, namely, the Central Bank of Kenya (CBK), the Capital Markets Authority (CMA), the Insurance Regulatory Authority (IRA), the Retirement Benefits Authority (RBA), and the Sacco Societies Regulatory Authority (SASRA), the youngest regulator established in 2008 (Graph 2).

\subsection{Financial Access Strands in Kenya}

The study uses the World Bank definition of the financial access strand along which FinScope and FinAccess surveys are conducted in a number of countries including Kenya. The definition enables the determination of the extent of financial inclusion in countries that conduct these surveys. Howev-

3 Nonetheless, this can be a matter of how the financial sector is defined and compartmentalized. 


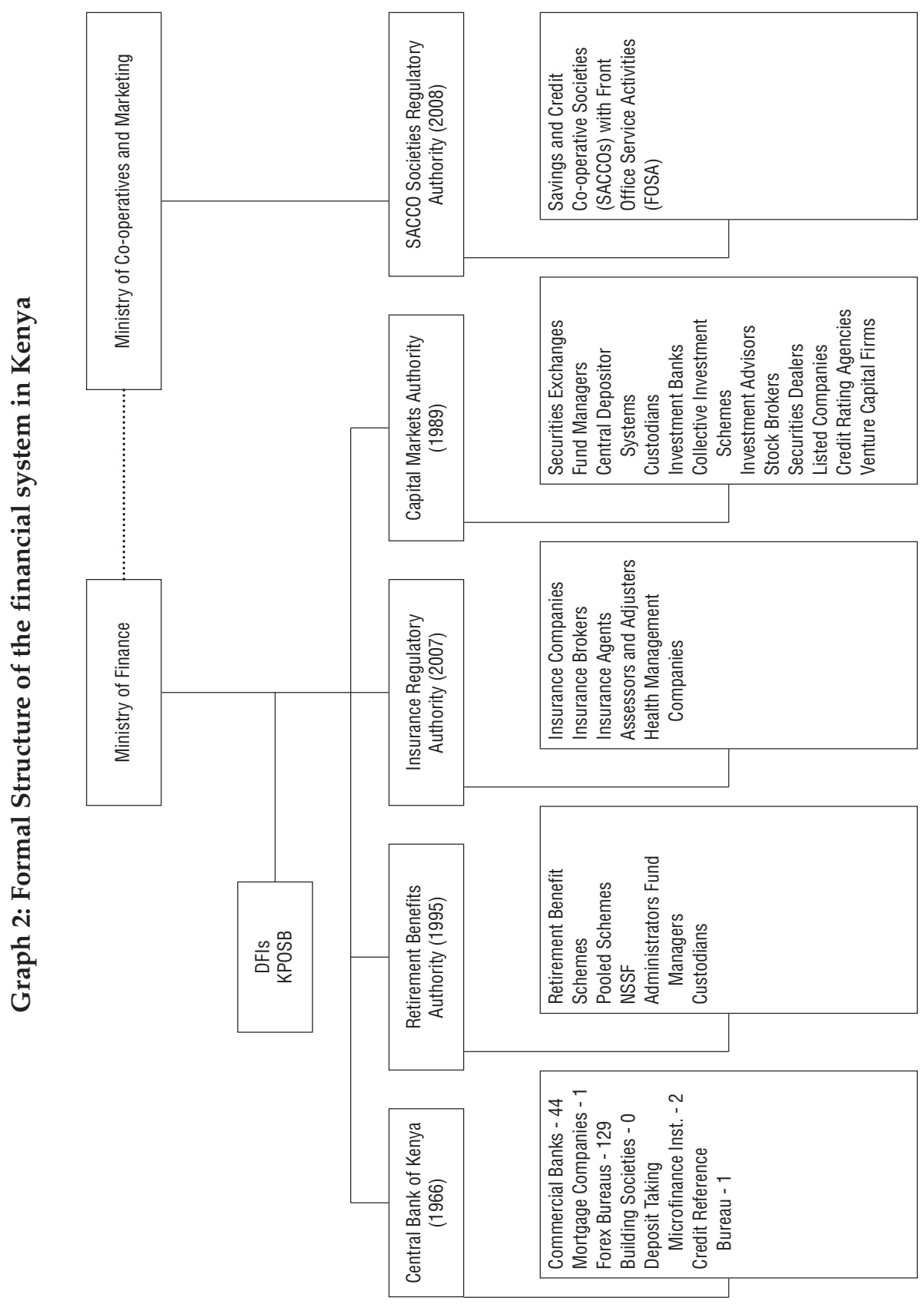


er, this is only one form of defining financial inclusion, which can be defined differently to appropriately correspond to the social, economic and geographic challenges unique to a country or region. For instance, it can be defined to mean "broad access to a portfolio of financial products and services that include loans, deposit services, insurance, pensions and payments systems as well as financial education and consumer protection mechanisms" as in Peru or simply as the "provision of access to financial services tailored to the needs of the population" for the case of Brazil. The Centre for Financial inclusion defines it as a state where all people who can use financial services have access to a full suite of quality financial services at affordable prices provided conveniently and with dignity to them. The FinScope and FinAccess surveys define financial inclusion in terms of four financial access strands defined as follows;

- Formal - use a bank, PostBank or insurance product.

- Semi-formal - use services from non-bank financial institutions such as SACCOs (Savings and Credit Cooperative Societies) and MFIs (Micro-finance Institutions).

- Informal - use informal financial service providers such as Accumulating Savings and Credit Associations (ASCAs), Rotating Savings and Credit Associations (RoSCAs) and groups/individuals other than family/friends.

- Excluded - use no formal, semi-formal and informal financial services.

Based on these definitions, the results of the FinAccess 2006 and 2009 surveys conducted in Kenya indicate that $22.6 \%$ of the population aged 18 years and older was formally financially included in 2009 compared to $18.9 \%$ in 2006. Usage of semi-formal financial services more than doubled from $7.5 \%$ in 2006 to $17.9 \%$ in 2009 (Chart 1). This improvement was mainly attributed to the mobile phone based M-pesa service provided by Safaricom, which was launched in March 2007. A total of 40.5\%, therefore, access formal financial services, representing approximately 7.6 million of an estimated adult population of 18.7 million in Kenya in 2009. Dependence on only informal financial services declined from $35.7 \%$ to $26.8 \%$ while the proportion excluded from any form of formal or informal financial services shrank from $38.4 \%$ in 2006 to $32.7 \%$ in 2009. In addition, access to financial services improved both in rural and urban areas; in urban areas, the formal strand increased from $32 \%$ in 2006 to $41 \%$ in 2009 . The proportion of those excluded from financial services also dropped in both; the drop was more marked in urban areas where it declined by about half (Chart 2). 
Chart 1:

Financial Access Strand

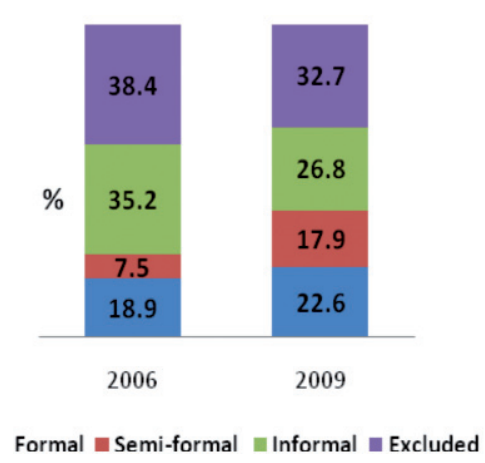

Chart 2:

Changes in Financial Access Strand by Region

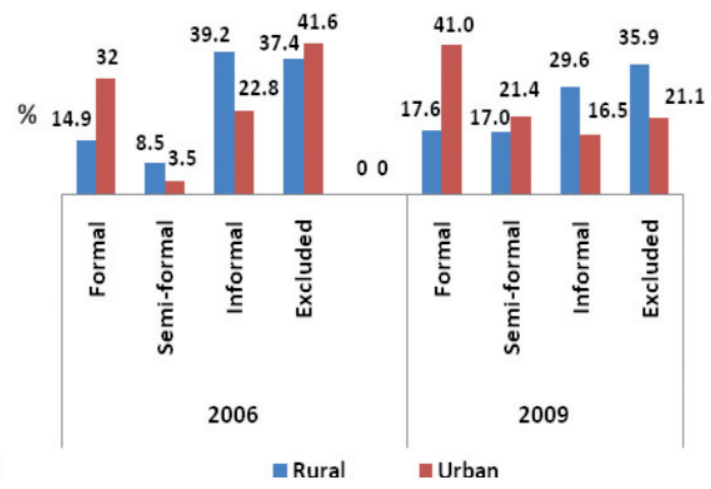

\section{LITERATURE REVIEW}

Literature in this area is still scanty and relatively new. Most past studies have concentrated on determining extent of financial inclusion or exclusion as the case may be without adequate consideration as to factors that determine users' choices of financial servicing modes that exist. Ouma (2002) examined the choice problem amongst entrepreneurs of the MSMEs in urban Kenya ${ }^{4}$. The study's findings illustrated that both institutional and individual attributes mattered for this category of users of financial services.

For instance, the study illustrates that as the amount of loan demanded increases, the likelihood of borrowing from the informal sector decreases compared to the formal implying that small loans are characteristic of informal lenders. Choosing to borrow from the informal financial markets also falls with increase in days of loan processing. Thus bureaucratic loans are a feature of formal finance, which are unlikely to serve credit needs of MSME entrepreneurs who usually demand quick loans to enable them to take advantage of emerging business opportunities that require quick disbursements. Increase in age also reduces the likelihood of borrowing from informal financial markets, also corroborated by Atieno (1999). Young MSME entrepreneurs are, therefore, more likely to borrow from informal lenders mainly because they have no credit history, no tangible collaterals and lack social networks that can enable them to benefit from formal group credit us-

4 The sample used to conduct the study was drawn from the sprawling Gikomba and Kibuye open air markets in Nairobi and Kisumu, respectively. 
ing social networks of the group as collateral substituting for traditional security, which they usually lack.

In analyzing institutional and personal attributes that influence choices of households amongst various savings modes, Ouma and Roesner (2003) found out that level of education, minimum account balance or membership registration fee, number of dependants, household and income exert significant influence on MSME entrepreneurs choices of institutions they save with. More years of formal education motivate them to save with formal financial institutions because of their relatively higher level of awareness of benefits derivable therefrom and risks associated with informal savings. On the other hand, the higher the level of dependency, the more likely the proprietors are to save with formal financial institutions to reduce cumulative exposure of their dependants to unnecessary risks when they can minimise or avoid it. Savings in formal financial institutions are accorded protection and transactions pertaining to them have recourse to law, which can be used to arbitrate any disputes that could arise. Informal savings modes do not enjoy this protection and have to rely on goodwill and trust of informal savings institutions. In addition, higher income levels dissuade MSME proprietors from saving with informal savings institutions implying that as incomes rise, the likelihood to save with formal savings modes increases too.

More recently, however, Kibet et al. (2009) analysing determinants of rural household savings amongst smallholder farmers, teachers and entrepreneurs found out that household income, occupation, and level of education positively influence savings behaviour. They would, therefore, save more as their levels of income and education rise. Households of businessmen save more than those of teachers and farmers because of frequent expenditure and revenue turnovers given the nature of their economic activity. On the other hand, access to credit, age and dependency ratio negatively affect savings. Households with easy access to credit will not save much because they would not rely heavily on their savings to fund their economic activities. The aging also experience reduced savings because their earning potential or productivity declines as one approaches retirement. In addition, expenditure increases with rising dependency ratio thereby reducing the amount a household would save.

\section{METHODOLOGY}

Literature illustrates dearth of access to financial services in developing economies such as Kenya. Kenya's financial access landscape reflects a large adult population accessing no formal financial services implying existence of 
factors influencing their accessibility. Given the Access Strand analogy provided by the financial access Surveys in Kenya, it is important to understand factors that influence their accessibility to services offered by the different strands. The choices made by the different households, it is assumed, maximize their utility. To be able to predict and explain these decisions, the study employs discrete choice models, given that the outcome variable is not continuous, to identify the factors that influence the choices that they make. Analysis will yield information on the direction and magnitudes of the effects of the influencing factors. The appropriate model to employ in this instance is a multiple choice problem given that the outcome variable has more than two options, namely, formal, formal other, informal and excluded financial access strands. Therefore, a multiple logistic regression model is used in the study.

In specifying the model, the outcome variable takes the value of $1,2,3$ or 4 if the option formal, formal other, informal or no strand is chosen, respectively. Predicting the probability that any of the options is chosen, however, depends on a vector of explanatory variables $\mathrm{Xi}$, and a vector of unknown parameters $\beta_{i}$. A multinomial logistic regression model is, therefore, used to estimate the significance of factors that determine the probability of households' choices as to which financial strand they will choose to access financial services from. The model has several desirable characteristics. It ensures, unlike the linear probability model, that the estimated probabilities will lie between 0 and 1 (Menard 1995, p. 13). In addition, the probabilities are linear in their parameters, i.e., an increase in magnitude of an independent variable will increase or decrease the probability of choosing any of the options or not.

The logistic regression model is generally specified as follows: ${ }^{5}$

$$
P(Y i)=\frac{e^{B 0+B 1 X 1+-+B k X k}}{1+e^{B 0+B 1 X 1+-+B k X k}}
$$

Where $P(Y i)$ is the probability that financial mode $i$ will be chosen say over mode $k$.

5 See for the description of the logistic regression model, Andreß, Hagenaars and Kühnel (1997), pp. 265-272; Menard (1995), pp.12-14; and Hosmer, and Lemeshow (1989), pp. 6-7. For reasons why OLS (Ordinary Least Squares) technique is inapplicable and the MLE (Maximum Likelihood Estimation) method is used see Menard (1995), pp.13-14 and Andreß, Hagenaars and Kühnel (1997), pp. 264-267. 
The model to be estimated for the choice of financial access strands is specified as follows:

$$
\mathrm{Y}_{i}=\mathrm{Y}_{i}\left(\mathrm{X}_{i}, \mathrm{Z}_{i}, \varepsilon_{i}\right)
$$

Where $Y_{i}=1$ if formal strand is chosen

$=2$ if formal other strand is chosen

$=3$ if informal strand is chosen

$=4$ if no strand is chosen

The reference category is option 4 , in other words, those who are excluded from formal and informal financial services.

And $X_{i}$ represents independent household attributes captured by FinAccess 2009 dataset, namely, age of respondent, level of education in years of formal education of the respondent, respondent's household size, minimum income per month, membership to a group, ownership of cattle, ownership of mobile phone, use of M-pesa and usage of any savings. $Z_{i}$, on the other hand, represents institutional characteristics captured by FinAccess 2009 dataset and includes rural or urban location of the institution and provision of a savings facility. $\boldsymbol{\varepsilon}_{i}$ is the error term.

\subsection{Data and Variable Definitions}

\subsubsection{Survey Methodology}

The study used the national financial access (FinAccess) survey datasets of 2006 and 2009. The FinAccess surveys were nationally representative with the samples drawn using operational National Sample Survey and Evaluation Program (NASSEP) IV. NASSEP IV was developed in 2002 based on the 1999 Population and Housing Census ${ }^{6}$ (Republic of Kenya 2000), which was multi-purpose and designed to provide estimates for various surveys. The 1999 Census was used to draw the samples ensuring eligible respondents aged 16 and above had equal chances of being selected.

Before the promulgation of the new constitution in 2010, Kenya was administratively divided into eight provinces, which were sub-divided into districts, each district into divisions, each division into locations and each lo-

6 The 1999 Population and Housing Census was the latest then before the 2009 Population and Housing Census (Republic of Kenya 2010) was conducted. A new NASSEP V is currently being constructed using the 2009 Census data and future FinAccess surveys will be conducted using the forthcoming NASSEP V. 
cation into sub-locations. The 1999 census, however, further sub-divided each sub-location into convenient areas called census Enumeration Areas (EAs) or clusters yielding a total of 62,000 EAs of which 1800 were selected to form the master frame using a two-stage stratified cluster sample format. The first stage involved selection of the EAs using probability proportional to size (PPS) method. The second stage involved the selection of households for various surveys. EAs were selected with a basis of one measure of size (MOS) defined as the ultimate cluster with an average of 100 households with a minimum of 50 and maximum of 149 households. Among the total 1800 clusters, 1260 were rural and 560 urban clusters.

The selection of the FinAccess sampled clusters was done systematically using the Equal Probability Selection Method (EPSEM) from eleven major domains, namely, national; provinces (Nairobi, Central, Coast, Eastern, North Eastern, Nyanza, Rift Valley and Western); region, (Rural and Urban); and to improve precision of the sample estimates into three other sub-domains, namely, cities (Nairobi and Mombasa), major municipalities (Kisumu, Nakuru, Eldoret and Thika), and other urban areas. The six major urban areas were observed to have a lot of variations across their populations. Consequently, further sub stratification was done to control for the apparent variation thus providing for five categories (1) Upper (2) Second Upper (3) Middle (4) Lower Middle and (5) Lower socio-economic categories.

The power allocation method was used to distribute the sample across the domains. The sample was first allocated to their respective provinces and urban-rural sub-domains. The sample was further allocated to the districts proportionate to their population and then to the major urban centres. From each selected cluster, an equal number of 12 households were selected systematically with a random start, thus allowing even sample distribution across the cluster. All persons aged 16 and older were eligible for the surveys. However, only one individual per household was sampled for interview using the Kish Grid random system of selection.

Based on this sampling methodology, therefore, the 2006 sample comprised 4418 individuals of which 4214 adults (aged 18 and above) were used in the analysis and the 2009 comprised 6598 individuals and 6343 adults were used in the analysis consequently excluding the youth aged 16 and 17 years old.

\subsubsection{Variable Definitions}

Determining households choices require data on the attributes of households and the financial access strands they choose to acquire financial services from. This study relies on the national household financial access 2009 
survey dataset. The data was collected using a structured questionnaire in the month of March 2009 and realized a national sample size of 6598. The variables used in the study are defined as follows:

The dependent variable is the choice amongst the financial access strands (as defined in section 1.3) from where to obtain financial services from or otherwise.

Independent variables are defined as follows:

- Yeduc: $\quad$ Number of years spent in formal education by respondent

The respondent's level of education, measured by years of formal education, is expected to influence favourably the choice of formal and semi-formal financial institutions for those with more years of formal education them being aware of their services, benefits and shortcomings. Those with no or few years of formal education may favour the informal for they suffer dearth of information about the formal and would feel intimidated by their bureaucratic documentation processes that demand some level of education to be comfortable with.

\section{- Totaldep: Total number of dependants on household head}

The variable captures the nuclear family and other relatives directly dependent on the household head for a living and staying under the same roof thereby capturing the social nature of African households. Ceteris paribus, the more the dependants the higher the household expenditure and the higher the need for frequent financial transactions, especially borrowings, to fund it. This frequency, particularly for consumption loans, may not be accommodated by formal financial institutions and such households may rely more on informal finance.

\section{- Cluster: Region defined as rural or urban}

Both formal and informal financial institutions exist in urban and rural areas albeit with an urban bias for formal financial institutions that find concentration in urban areas. This might favour their choice in urban areas and the informal in rural areas, especially where the formal do not exist or are sparse.

\section{- Use.sav: Usage of a savings facility}

Savings facility is defined in this case to mean that an opportunity to save is provided for. For instance, credit only financial institutions do not provide this facility implying that those who need to save miss the chance to and the availability of credit only financial institution does not therefore serve their financial need. 


\section{- Cattle: Ownership of cattle}

Cattle ownership was used as a proxy for wealth. The wealthy are likely to access formal financial services because their transactions are less risky and are protected by law. In addition, wealth forms collateral usually demanded to secure loans thereby guaranteeing easy access to formal loans for the wealthy.

- Age: $\quad$ Age of respondent in years

Age is important in accessing formal financial institutions. In Kenya for instance, unless under special circumstances, only adults can open an account implying the young are excluded and can therefore, only access informal financial services. Likewise, the aged poor without formal income would find accessing formal financial services difficult and will therefore meet their financial needs from the informal. Thus it is mainly the wealthy and the working class who can easily access formal financial services.

\section{- Mobil: $\quad$ Mobile Phone Ownership}

Mobile phones ownership is ubiquitous in Kenya. They improve and speed up communications. They will therefore enable quick follow-ups with financial institutions for instance, on loan applications and/or other services offered without making physical visits. Structured financial institutions with proper communications channels characteristic of formal financial institutions are major beneficiaries and this phenomenon greatly enhances their choice.

\section{- M-pesa: Usage of M-pesa service}

Although mobile phones ownership in Kenya is widespread, not all of them are M-pesa registered. However, the majority of them are. Being M-pesa compliant improves access to financial services. It enhances access to financial services without visiting the actual financial institutions, thus saving on costs and time, and facilitates both formal and informal financial transactions.

\section{- MinInc: Minimum income per month in Kenya shillings}

Actual income is usually difficult to obtain. Most studies therefore rely on proxies or estimates. For this study, minimum income variable came from the question, what is the minimum income you need to meet your normal monthly expenditures? The figure was corroborated by total expenditure for listed common monthly expenditure items, e.g., school fees, household bills (water, electricity, telephone - including mobile), groceries, clothing, medical, house rent, etc. 
- Gmember: Membership to a group

The respondent is a member of a group, either a women group a keen to a "merry go round" or groups formed through the intervention of a MFI for the purpose of providing financial services to a group and not an individual and thus cover some of the inherent risks by the whole group being liable, for instance to a loan. Thus when a member defaults on his or her portion of the loan, the whole group is liable for it.

\section{FINDINGS AND DISCUSSIONS}

The empirical findings of the estimation are shown in Table 1 below. The results show that a strong relationship between the endogenous and exogenous variables exists. This is confirmed by the Pseudo- $\mathrm{R}^{2}$ statistic. The results reveal that the likelihood of accessing formal financial services is influenced by ownership of cattle, mobile phone, use of M-pesa, access to savings facility, levels of education, age, level of dependency and also group affiliations. Cattle ownership as a proxy for wealth demonstrating that those with wealth are likely to access formal financial services for the simple reason that they are less risky and their transactions have recourse to law. Mobile phone ownership and being able to use M-pesa has pushed more and more people to formal financial services. As observed in the FinAccess 2009 report, M-pesa service has promoted formal financial inclusion and this is likely to be the case, as more formal financial institutions embrace M-pesa and other mobile phone based financial services providers to facilitate their transactions. This is indeed appetizing for formal financial institutions to leverage on the mobile phone technology given that a good proportion of the population already have mobile phones, and for those who do not have, they can quickly access the M-pesa like services from friends and relatives.

This study also confirms findings of pioneer studies that improved access to formal education is positive for enhancing formal financial inclusion. As people get more educated, they appreciate the services of the formal financial access strand; they are less risky; are cheaper; and in most cases have the resources to meet the demands of their customers once their requirements are met. And as one ages, the likelihood of going to the formal financial access strand for financial services increases too. This vindicated earlier studies which showed that as people age they want more security for their hard earned earnings. In addition, they also become more eligible for the services of the formal strand because of their capacity to raise demanded collateral given assets acquired over time. 
Table 1: Results of a Logistic Regression Estimation of attributes influencing usage of financial services of different financial access strands in Kenya

\begin{tabular}{|c|c|c|c|c|c|}
\hline \multicolumn{6}{|c|}{ Multinomial Logistic Regression - Maximum Likelihood Parameter Estimates } \\
\hline Logit & Variables & Coeff. (B) & Std.Error & Wald & Sig. \\
\hline \multirow[t]{11}{*}{ Formal } & Constant & -13.263 & 1.838 & -7.220 & 0.000 \\
\hline & Cattle & 1.209 & 0.553 & 2.190 & 0.029 \\
\hline & Mobil & 2.720 & 0.499 & 5.450 & 0.000 \\
\hline & M-pesa & 1.333 & 0.388 & 3.430 & 0.001 \\
\hline & Use.sav & 2.606 & 1.045 & 2.490 & 0.013 \\
\hline & Age & 0.061 & 0.012 & 5.150 & 0.000 \\
\hline & Yeduc & 0.658 & 0.139 & 4.750 & 0.000 \\
\hline & Cluster & 0.930 & 0.892 & 1.040 & 0.297 \\
\hline & Totaldep & -0.229 & 0.084 & -2.720 & 0.007 \\
\hline & MinInc & 0.000 & 0.000 & -0.400 & 0.689 \\
\hline & Gmember & 2.296 & 0.324 & 7.090 & 0.000 \\
\hline \multirow[t]{11}{*}{ Formal Other } & Constant & -5.623 & 0.564 & -9.980 & 0.000 \\
\hline & Cattle & 0.596 & 0.150 & 3.970 & 0.000 \\
\hline & Mobil & 1.708 & 0.141 & 12.120 & 0.000 \\
\hline & M-pesa & 2.327 & 0.150 & 15.550 & 0.000 \\
\hline & Use.sav & 0.768 & 0.168 & 4.570 & 0.000 \\
\hline & Age & 0.035 & 0.004 & 8.250 & 0.000 \\
\hline & Yeduc & 0.290 & 0.053 & 5.510 & 0.000 \\
\hline & Cluster & -0.094 & 0.385 & -0.240 & 0.808 \\
\hline & Totaldep & -0.088 & 0.026 & -3.370 & 0.001 \\
\hline & MinInc & 0.000 & 0.000 & 1.860 & 0.062 \\
\hline & Gmember & 2.877 & 0.168 & 17.150 & 0.000 \\
\hline \multirow[t]{11}{*}{ Informal } & Constant & -1.483 & 0.479 & -3.100 & 0.002 \\
\hline & Cattle & 0.005 & 0.116 & 0.040 & 0.965 \\
\hline & Mobil & 0.211 & 0.133 & 1.580 & 0.113 \\
\hline & M-pesa & 0.510 & 0.152 & 3.360 & 0.001 \\
\hline & Use.sav & 1.260 & 0.154 & 8.180 & 0.000 \\
\hline & Age & -0.002 & 0.004 & -0.570 & 0.566 \\
\hline & Yeduc & -0.094 & 0.048 & -1.950 & 0.051 \\
\hline & Cluster & -0.172 & 0.351 & -0.490 & 0.625 \\
\hline & Totaldep & -0.066 & 0.022 & -3.020 & 0.003 \\
\hline & MinInc & 0.000 & 0.000 & -0.910 & 0.362 \\
\hline & Gmember & 3.538 & 0.157 & 22.490 & 0.000 \\
\hline \multirow[t]{3}{*}{ Pseudo $R^{2}$} & Cox and Snell & \multirow{3}{*}{\multicolumn{4}{|c|}{$\begin{array}{l}0.579 \\
0.523 \\
0.415\end{array}$}} \\
\hline & Nagelkerke & & & & \\
\hline & McFadden & & & & \\
\hline
\end{tabular}


Being in a group too enhances the likelihood that one will deal with a formal financial institution. Most groups keep their savings with these institutions while some of them are formed to obtain group credit by being able to raise and rely on group capital and be jointly liable for the loan corroborating earlier work by Gollier et Al. (2000) and Ghatak (2000) among others. Thus, those who cannot access services of the formal financial access strand as individuals, do so as a group, which improves formal financial inclusion.

The level of dependency, however, negatively impacts on access to formal financial services. Thus the larger the household size, the more likely it is to be excluded from formal financial intermediation because the nature of expenditures incurred are rapid demanding very convenient sources of funding like the informal financial services arrangements, which are comparatively less bureaucratic. Their frequent expenditures also mean that no meaningful savings can take place in, especially, formal financial institutions to attract interest because some minimum period, e.g., six months may be required for interest payments and some minimum amount of deposit maintained in the account. With frequent expenditures the two conditions are unlikely to be met.

There are similarities with the formal other financial access strand. The likelihood of accessing its financial services improves with ownership of cattle and mobile phones, being able to use M-pesa and offer of a savings facility. More years of education and being an adult also improve access to semiformal financial products. Group affiliation is very important for this group. This is where most MFIs and donor or government sponsored credit schemes abound and use group credit methodology to extend financial services, particularly credit. It implies that with social capital emanating from the groups mitigating against poor credit worthiness of individuals, access to financial services of the semi-formal financial sector become possible. The outcomes also suggest that being in urban or rural areas is immaterial since these institutions are found in both. However, this could be the import of group affiliations that enable those who on their own would not access financial services whether in urban or rural areas.

The likelihood of accessing informal financial services, on the other hand, does not depend on rural or urban area location implying informal financial arrangements, just like the formal financial institutions, exist in both. Neither is the likelihood to their access influenced by cattle ownership and age. Being young or old matters little for the informal financial sector services because they can be accessed by all. Age therefore is not used to discriminate and neither is wealth because the unique services from both strands benefit the wealthy who prefer to consume the combination. Acquiring more formal education and larger household sizes, however, reduces the likelihood of ac- 
cessing informal financial arrangements. More education negatively affects access to informal financial services. It depicts a flight of the educated to more formal financial markets as they access better employment opportunities and higher incomes. Nonetheless, large households incur relatively large recurrent expenditures and therefore may suffer reduced ability to save and repay loans and tend to be excluded from financial services provision across all the financial access strands and thus remain unbanked.

However, being able to use M-pesa, access a savings facility and affiliation to groups improves the likelihood of accessing informal financial strand's services. The art of building social capital was learnt by other financial sector institutions from informal financial intermediation, which rely a lot on the virtues of trust, reciprocity and networks to thrive. M-pesa has brought in added advantages of speed, low risk and reduced costs to rejuvenate the informal financial sector and this has been duly embraced.

It is evident therefore that wealth, mobile phone, ease of access to a savings facility, and being affiliated to a group reduces financial exclusion. However, large household sizes, an indicator of high dependency, acerbate financial exclusion.

\section{CONCLUSION AND IMPLICATIONS FOR POLICY}

Households access financial services form all the three financial access strands: formal, formal other and informal. However, not all do. About one third does not access any of the financial services they offer. Their access to and lack of access to the financial services are attributable to various factors.

Wealth as measured by ownership of cattle, modern technology as demonstrated by mobile phone ownership and being able to use M-pesa, group affiliation and mobilization of funds individually or through associations and/or groups are key factors that enhance financial inclusion. Ageing, nonetheless, enhances formal financial inclusion but at the expense of informal financial inclusion, just like formal education does. These are the factors to pay attention to in order to attract excluded households into accessing financial services from any of the strands, but more so from the formal financial access strand.

However, large household sizes and, therefore, high dependency ratios worsen financial inclusion. As indications show that fertility in Kenya is falling, i.e., total fertility rate (TFR ${ }^{7}$ ) fell from a high of 8.1 births per woman

7 Total Fertility Rate (TFR) measures the number of children on average a woman who is at the beginning of her childbearing years will give birth to by the end of her reproductive period. 
in 1975-78 to 4.6 in 2006-08 (Economic Survey, 2010), dependency ratios are falling and therefore financial inclusion is bound to rise. These conclusions have the following policy implications;

- Use of mobile phones to deliver financial services should be enhanced and therefore adoption of mobile phone technology and M-pesa type technology need to be embraced by financial services providers. The study also recommends that waiver of import duty on mobile phones and their accessories effected by the Finance Bill of 2009 should be maintained to continuously make them more affordable to the majority, who form a larger proportion of the unbanked.

- Mobile phone companies should consider more innovative marketing schemes, e.g., contractual ownership to spur their usage and recoup their costs from usage because the phones have proved their usefulness beyond simple communications. For instance, they have been used by financial services providers to innovate new products and processes of offering the services. Consequently, the expanded array of services provided through the phones would enable recovery of their costs from their enhanced usage.

- Investment in education is good for improving access to financial services. More emphasis, however, needs to be placed on financial education because beneficial usage of financial services require not only formal education, but also a good understanding of the technical issues that go with their provision.

- Funds mobilization through the provision of a savings facility is also important to the expansion of financial inclusion, reinforcing lessons from literature that the poor, the majority of whom form the unbanked population, do save. Institutions that offer designed savings facility such as the initiative to allow MFIs mobilize savings or allowing banks provide services through agents rather than the expansive brick and mortar branches are sure ways to expanding financial inclusion. DTMFIs whose licensing began in $2009^{8}$ are, therefore, bound to rapidly enhance financial inclusion, and efforts to license many of them should be intensified.

8 The first Deposit Taking Microfinance Institution (DTMFI) in Kenya, Faulu Kenya, was licensed on May 21, 2009. 


\section{References}

Andress H.J., J.A. Hagenaars and S. Kuehnel, 1997, Analyze von Tabellen und Kategorialen Daten: Lo-lineare Modelle, Latente Klassenanalyze, Logistische Regression und GSK-Ansatz, Springer-Verlag, Berlin.

Atieno R., 1999, “Access to Credit by Women in Agribusiness Trade: Empirical Evidence on the Use of Formal and Informal Credit Sources in Rural Kenya", Paper presented at the Conference on Roles, Constraints and Potentials of Women in Agricultural Development, The Centre for Development Research (ZRF), Bonn, August.

Central Bank of Kenya (CBK) and Financial Sector Deepening (FSD) Kenya, 2009, Financial Access National Survey: Dynamics of Kenya's changing Financial Landscape, June.

Central Bank of Kenya (CBK) and Financial Sector Deepening (FSD) Kenya, 2007, Financial Access in Kenya: Results of the 2006 National Survey, October.

Ghatak M., 2000, "Screening by the Company You Keep: Joint Liability Lending and the Peer Selection Effect", The Economic Journal, Vol. 11, No. 465, pp. 601-631.

Gollier C. and B. Armendariz de Aghion, 2000, "Peer Group Formation in Adverse Selection Model", The Economic Journal, Vol. 110, No. 46, No. 5, pp. 632-643.

Hosmer Jr. D.W. and S. Lemeshow, 1989, Applied Logistic Regression, John Wiley and Sons, New York.

Kibet L.K., B.K. Mutai, D.E. Ouma, S.A. Ouma and G. Owuor, 2009, “Determinants of Household Saving: Case study of Smallholder Farmers, Entrepreneurs and Teachers in Rural Areas in Kenya", Journal of Development and Agricultural Economics, Vol. 1, No. 7, pp. 137-143.

Levine R., 1997, "Financial Development and Economic Growth: Views and Agenda", Journal of Economic Literature, Vol. 35, pp. 688-726.

Menard S., 1995, Applied Logistic Regression Analysis: Quantitative Applications in the Social Sciences, Sage Publications, Inc., Thousand Oaks.

Ouma A.S., 2002, "Financial Sector Dualism: Determining Attributes for Small and Micro Enterprises in Urban Kenya: A Theoretical and Empirical Approach based on Case Studies in Nairobi and Kisumu", Shaker Verlag, Aachen.

Ouma A. S. and H.J. Roesner, 2003, "Savings Institutions that Count for Small and Micro Enterprises: the Case of Urban Kenya", African Review of Money, Finance and Banking, pp. 23-46.

Republic of Kenya, 2010, Economic Survey, Kenya National Bureau of Statistics, Government Printer, Nairobi.

Republic of Kenya, 2010, 2009 Kenya Population and Housing Census, Government Printer, Nairobi.

Republic of Kenya, 2000, 1999 Kenya Population and Housing Census, Government Printer, Nairobi. 
Republic of Kenya, 2007, Kenya Vision 2030, Ministry of Planning and National Development (MPND) and the National Economic and Social Council (NESC), Government Printer, Nairobi.

\section{Résumé}

Cette étude utilise les données des enquêtes (FinAccess) sur l'accès national aux services financiers (2006 et 2009) pour examiner les facteurs qui influent sur les choix de services financiers que les ménages font. Les résultats indiquent que l'accès des ménages aux services financiers est fondé sur les niveaux d'éducation, l'accès à un service d'épargne, la disponibilité des services M-Pesa, l'âge, l'appartenance de groupe et la richesse. L'étude indique également que environs un tiers de la population adulte n'utilise aucune forme de services financiers disponibles. Sur la base des résultats, l'étude recommande des stratégies de marketing novatrices visant à étendre l'utilisation des téléphones mobiles, qui sont utiles au-delà du service de voix et récupèrent les coûts à travers leur utilisation accrue, l'augmentation des investissements dans l'éducation financière, et une meilleure conception par le secteur privé de produits financiers appropriés pour la majorité qui n'est pas bancarisée. 
